\section{Tropical Journal of Pathology and Microbiology}

2020 Volume 6 Number 1 January

\title{
Detection of dengue virus in Eastern India
}

\author{
Mukherji T. ${ }^{1}$, Mukherji MB. ${ }^{2 *}$ \\ DOI: https://doi.org/10.17511/jopm.2020.i01.12
}

1 Tamasi Mukherji, Assistant Professor, Department of Microbiology, KPC Medical College and Hospital, Kolkata, West Bengal, India. https://orcid.org/0000-0003-2119-2315

2* Mayur Bahan Mukherji, Associate Professor, Department of Medicine, KPC Medical College and Hospital, Kolkata, West Bengal, India.

Background: Dengue fever is a mosquito-borne tropical disease caused by the dengue virus. Symptoms typically begin three to fourteen days after infection. The virus has four serotypes; infection with one type usually gives lifelong immunity to that type, but only short-term immunity to the others. Subsequent infection with different dengue virus increases the risk of severe complications. Methods: There are three methods followed in particular to detect the dengue virus: (A) Dengue NS1 AG Microlisa is designed for in-vitro qualitative detection of Dengue NS1 antigen in human serum or plasma and is used as a screening test for testing of collected blood samples suspected for DENGUE. This method detects all four subtypes; DEN1, DEN2, DEN3 \& DEN4 of Dengue Virus. Results: Among 1860 dengue samp1es, 420 sâmp1es were found to be NS1Ag positive 160 samples were found to be IgM positive and 24 samples were found to be IgG positive. Rest Samples negative for all three parameters. Conclusion: Dengue is a mosquito borne viral infection causing a severe flu like illness and sometimes causing a potentially lethal complication called severe dengue. The incidence of dengue has increased 30 fold over the last 50 years. Up to 50-100 million infections are now estimated to occur annually in over 100 endemic countries, putting almost half of the world's population at risk. If sever dengue fever can damage the lungs, liver or heart or multiorgan failure.

Keywords: Dengue virus, NS1 Antigen, IgM antibody, IgG antibody, Dengue hemorrhagic fever, Dengue shock syndrome, ELISA

\section{Corresponding Author}

Mayur Bahan Mukherji, Associate Professor, Department of Medicine, KPC Medical College and Hospital, Kolkata, West Bengal, India. Email: mayur.mukherji@yahoo.com
How to Cite this Article To Browse Mukherji T, Mukherji MB. Detection of dengue virus in Eastern India. Trop J Pathol Microbiol. 2020;6(1):76-82. Available From https://pathology.medresearch.in/index.php/jopm/ar ticle/view/417

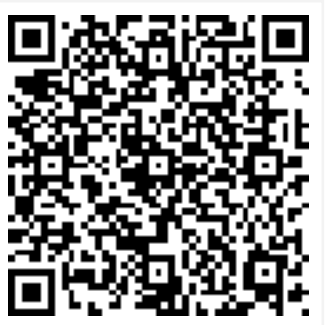

\section{Introduction}

The mosquito-borne dengue viruses (serotype 1-4) cause dengue fever, a severe flu-like illness. The disease is prevalent in the third world tropical regions and spreading to subtropical developed countries - including

(c) 2020 by Tamasi Mukherji, Mayur Bahan Mukherji and Published by Siddharth Health Research and Social Welfare Society This is an Open Access article licensed under a Creative Commons Attribution 4.0 International License https://creativecommons.org/licenses/by/4.0/ unported [CC BY 4.0]. 
Primary infection with dengue virus results in a selflimiting disease characterized by mild to high fever lasting 3 to 7 days, severe headache with pain behind the eyes, muscle and joint pain, rash and vomiting. Secondary infection is the most common form of disease in many parts of the Southeast Asia and South America [2].

This form of the disease is more serious and can result in DHF and DSS. The major clinical symptoms can include high fever, hemorrhagic events, and circulatory failure, and the fatality rate can be as high as $40 \%$. Early diagnosis of DSS is particularly important, as patients may die within 12 to 24 hours if appropriate treatment is not administered.

Primary dengue virus infection is characterized by elevations in specific IgM antibody levels 3 to 5 days or specific NS1 antigen levels 0 to 9 days after the onset of symptoms; this generally persists for 30 to 60 days or 15 days. IgG levels also become elevated after 10 to 14 days and remain detectable for life. During secondary infection, while IgG levels rise rapidly from 1 to 2 days after the onset of symptoms.

Dengue virus (DENV) is the cause of dengue fever. It is a mosquito-borne single positive-stranded RNA virus of the family Flaviviridae genus Flavivirus. Four serotypes of the virus have been found, all of which can cause the full spectrum of disease. Nevertheless, scientists understanding of dengue virus may be simplistic, as rather than distinct antigenic groups there appears to be a continuum [3].

This same study identified 47 strains of dengue virus. The dengue virus has increased dramatically within the last 20 years, becoming one of the worst mosquito-borne human pathogens tropical countries have to deal with [4]. Since no other animals have contracted the disease, research into this disease is limited.

There are four antigenically different serotypes of the virus (although there is report of 2013 that a fifth serotype has been found):

- DENV-1

- DENV-2

- DENV-3

- DENV-4

Here, a serotype is a group of viruses classified together based on their antigens on the surface of the virus. These four subtypes are different strains
Of dengue virus that have $60-80 \%$ homology between each other. The major difference for humans lies in subtle differences in the surface proteins of the different dengue subtypes[5]. The first infection causes mostly minor disease, but secondary infections has been reported to cause severe diseases (DHF or DSS) in both children and adults. This phenomenon is called AntibodyDependent Enhancement [6].

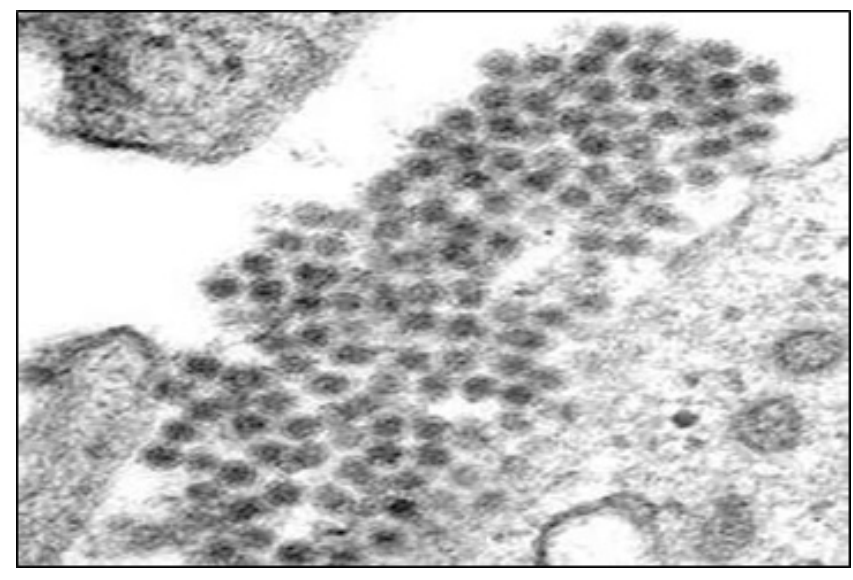

Fig-1: Microscopic view of the Dengue virus

\section{Classification}

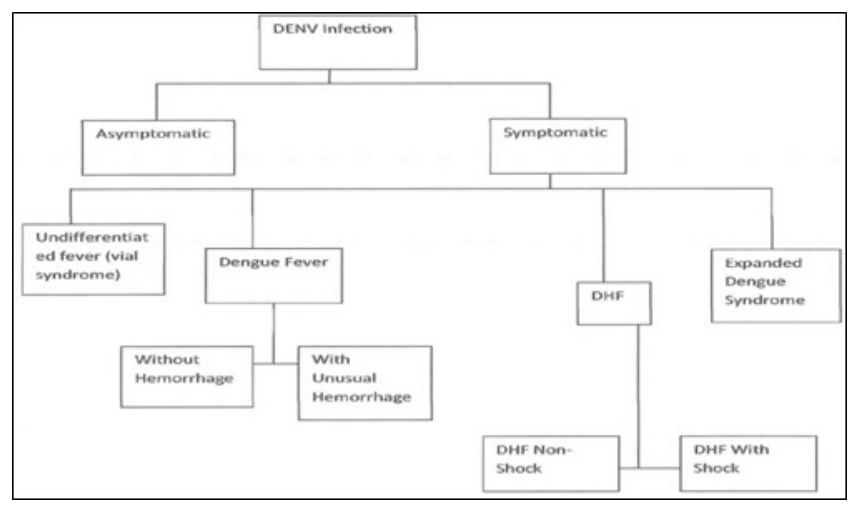

Fig-2: Classification of the Dengue virus disease.

DSS - Dengue Shock Syndrome

DHF- Dengue Hemorrhagic Fever Dengue has now become hyperendemic in India with co-circulation of all the four serotypes. Herein, the present study reported an unprecedented outbreak which occurred during August to October 2011 in Odisha, eastern India [7]. This is the first report of a large epidemic in Odisha. Detailed serological and molecular investigation was carried out to identify the aetiology. Almost half of the samples were found to be dengue antigen (NS1) positive. Further molecular assays revealed circulation of mixed dengue serotypes (DENV-2 and DENV-3) [8]. 
The actual numbers of dengue cases are underreported, and many cases are misclassified [9]. One recent (2013) estimate indicates that 390 million dengue infections occur every year (95\% credible interval 284-528 million), of which 96 million (67-136 million) manifest clinically (with any severity of disease) [10].

Another (2012) study, of the prevalence of dengue, estimates that 3.9 billion people in 128 countries are at risk of infection with dengue viruses [11].

\section{Materials and Methods}

Study type: Prospective July-December 2019.

Sample selection: The selection of samples for present study was carried out. The sample was selected through indoor and OPD (according to doctors prescribe.)

\section{Sample collection and handling:}

- Human serum or plasma sample should be used for the test.

- Sample collection was carried out in accordance with relevant guidelines and regulation. About $3.5 \mathrm{~m} 1$ of blood was drawn from patients by vein puncture.

- Specimen should be free of microbial contamination and should be maintained at 2$8^{\circ} \mathrm{C}$ for $1-2$ days while handling or frozen at $-20^{\circ} \mathrm{C}$ or lower for long time.

Specimen processing: Most frozen samples will perform well when thawing is allowed in a vertical position in the rack. Do not shake the sample. This allows particles to settle to the bottom. If a centrifuge is available, the sample should be centrifuged (5000rpm for 5 minutes.)

Transportation: If the specimen is to be transported, it should be packed in compliance with the current government regulations regarding transport of aetiologic agents.

Note: Sample labeling is very important because there may occur a system error.

\section{Qualitative Detection of Dengue Virus (DENV)}

\section{Method I}

Dengue IgM/IgG Microlisa test-The mosquitoborne dengue viruses (serotype 1-4) cause dengue fever, a saver flu-like illness. The disease is prevalent in third world tropical regions and
Spreading to subtropical developed countries including the United States.

Primary dengue virus infection is characterized by elevations in specific 1gM antibody levels 3-5 days after the onset of symptoms; this generally persists for 30-60 days. IgG levels also become elevated after 10-14 days and remain detectable for life.

During secondary infection $1 \mathrm{gM}$ levels generally rise more slowly and reach lower level than in primary infection while IgG levels rise rapidly from 1-2 days after the onset of symptoms.

\section{Principle}

Dengue IgM / IgG Microlisa test is an enzyme immunoassay based on "MAC capture ELISA".

Anti-human IgM antibodies are coated on to microtitre wells Specimens and controls are added to the microtitre wells and incubated.

Antibody to dengue if present in the specimen; will bind to the anti-human 1gM antibodies absorbed on the surface of the wells. The plate is then washed to remove unbound materials.

HRPO (Horses-radish peroxidase) conjugated Dengue antigen (DEN 1-4) is added to each well. This dengue antigen conjugate will bind to Dengue specific IgM Antibodies which is complex with antihuman IgM Antibodies.

Finally substrate solution containing chromogen and $\mathrm{H} 2 \mathrm{O} 2$ is added to the well and incubated.

A blue color will develop in proportion to the amount of Dengue Antibodies present in the specimen. The color reaction is stopped by the stop solution.

The enzyme-substrate reaction is read by EIA reader for absorbance at a wavelength of $450 \mathrm{~nm}$ (also $360 \mathrm{~nm}$.) If sample does not contain $1 \mathrm{gM}$ antibodies then enzyme-conjugate will not bind and the solution in the well will be either colorless or only a faint background color develops.

\section{Results}

The kit has been evaluated with known panel of Dengue 1gM Positive and Negative samples. The samples included cross-reacting samples; EspteinBarr Virus, Leptospira, Malaria, Hepatitis A, Influenza A and B, Salmonella typhi.

Following are the in-house evaluation: 


\begin{tabular}{|c|c|c|c|}
\hline $\begin{array}{c}\text { No. of } \\
\text { samples }\end{array}$ & $\begin{array}{l}\text { Sample } \\
\text { O.D. }\end{array}$ & $\begin{array}{c}\text { Dengue IgM Microlisa Value } \\
\text { (units) }\end{array}$ & Status \\
\hline 1. & 0.1691 & 6.0 & $\begin{array}{l}\text { Dengue } \\
\text { Negative }\end{array}$ \\
\hline 2. & 1.0899 & 38.9 & $\begin{array}{l}\text { Dengue } \\
\text { Positive }\end{array}$ \\
\hline 3. & 0.4910 & 17.5 & $\begin{array}{l}\text { Dengue } \\
\text { Positive }\end{array}$ \\
\hline 4. & 0.0018 & 0.06 & $\begin{array}{l}\text { Dengue } \\
\text { Negative }\end{array}$ \\
\hline 5. & 1.2705 & 45.4 & $\begin{array}{l}\text { Dengue } \\
\text { Positive }\end{array}$ \\
\hline 6. & 0.0062 & 0.22 & $\begin{array}{l}\text { Dengue } \\
\text { Negative }\end{array}$ \\
\hline 7. & 1.0519 & 37.6 & $\begin{array}{l}\text { Dengue } \\
\text { Positive }\end{array}$ \\
\hline 8. & 0.0563 & 2.0 & $\begin{array}{l}\text { Dengue } \\
\text { Negative }\end{array}$ \\
\hline 9. & 0.0014 & 0.05 & $\begin{array}{l}\text { Dengue } \\
\text { Negative }\end{array}$ \\
\hline 10. & 0.6371 & 22.7 & $\begin{array}{l}\text { Dengue } \\
\text { Positive }\end{array}$ \\
\hline
\end{tabular}

Sensitivity: $50 \%$

Specificity: $50 \%$

Precision: Within-run and between-run precisions have been determined by testing 10 replicates of five samples:

1 negative and 4 dengue 1gM positive; 2 weak positive, 1 medium positive and 1 strong positive. The C.V (\%) of negative, weak positive, medium positive and strong positive values were within $10 \%$.

A. Calculation of Dengue 1gM units: Calculate by multiplying the sample O.D ratio by 10 .

B. Considering one O.D value from the observation table as 1.0899

Cut off Value $=0.28$

Sample O.D ratio O.D/ Cut off Value $=1.0899 / 0.28$ $=3.8925$

Dengue $1 \mathrm{gM}$ units $=$ Sample O.D ratio $* 10=$ $3.8925 * 10=38.92$

Therefore, $\mathbf{3 8 . 9 2}$ units will portray as Dengue Positive.

\section{Interpretation of Results}

- If the Dengue IgM Units is < 9 then interpret the sample as Negative for Dengue $1 \mathrm{gM}$ antibodies.
- If the Dengue IgM Units is between 9-11 then interpret the sample as Equivocal for Dengue IgM antibodies.

- If the Dengue IgM Units is between > 11 then interpret the sample as Positive for Dengue IgM antibodies.

\section{Test Validity}

- NC O.D. must be $<0.3$. If it is not so, the run is invalid and must be repeated.

- PC O.D. must be $>10$. If it is not so, the run is invalid and must be repeated.

- Mean calibrator O.D must be $>/ 0.35$. If it is not so, the run is invalid and must be repeated.

- Cut off value must be $>/ 1.5 \times$ NC O.D. If it is not so, the run is invalid and must be repeated.

- Ratio of PC O.D. / cut off must be > 1.1. If it is not so, the run is invalid and must be repeated.

\section{Limitations of the Test}

- The test should be used for detection of $1 \mathrm{gM}$ antibodies of Dengue in human serum.

- This is the only screening test and will only indicate the presence or absence of Dengue antibodies in the specimen. All reactive samples should be confirmed by confirmatory test. Therefore for a definitive diagnosis, the patients clinical history, symptomatology as well as serological data should be considered. The results should be reported only after complying with the above procedure.

False positive results can be obtained due to cross reaction with Epstein-Barr virus, Leptospira, Malaria, Hepatitis A, Influenza A \& B, Salmonella typhi, Japanese encephalitis, West Nile virus disease. This occurs in less than $1 \%$ of the sample tested.

\section{Discussion}

Dengue is a mosquito-borne viral infection causing a severe flu-like illness and, sometimes causing a potentially lethal complication called severe dengue. The incidence of dengue has increased 30-fold over the last 50 years. Up to 50-100 million infections are now estimated to occur annually in over 100 endemic countries, putting almost half of the world's population at risk [12].

If severe, dengue fever can damage the lungs, liver or heart, blood pressure can drop to dangerous levels, causing shock and, in some cases, death with multi organ failure. 
Approximately 2.5 billion people live in dengue-risk regions with about 100 million new cases each year worldwide [13]. The cumulative dengue diseases burden has attained an unprecedented proportion in recent times with sharp increase in the size of human population at risk. Dengue disease presents highly complex pathophysiological, economic and ecologic problems.

In India, the first epidemic of clinical dengue-like illness was recorded in Madras (now Chennai) in 1780 and the first virologically proved epidemic of dengue fever (DF) occurred in Calcutta (now Kolkata) and Eastern Coast of India in 1963-1964 [14]. Its viral cause and spread were understood by the early 20th century. Apart from eliminating the mosquitoes, work is ongoing for medication targeted directly at the virus. It is classified as a neglected tropical disease.

One dengue fever vaccine, Dengvaxia, is currently approved for use in those ages 9 to 45 years old who live in areas with a high incidence of dengue fever [15]. The vaccine is given in three doses over the course of 12 months.

The World Health Organization stresses that the vaccine is not an effective tool, on its own, to reduce dengue fever in areas where the illness is common [16]. Controlling the mosquito population and human exposure is still the most critical part of prevention efforts.

Methods such as one step, real time RT-PCR or nested RT-PCR are now widely used to detect dengue viral gene in acute - phase serum samples. Acute infections can also be laboratory confirmed by sero-conversion from negative to positive IgM antibody to dengue or demonstration of a fourfold or greater increase in IgG antibody titers in paired serum specimen [17].

Patients who have IgM antibodies to dengue detection in their serum specimen via IgM antibody capture enzyme-linked immunosorbent assay (MACELISA).

01. A negative RT-PCR in the acute phase specimen or

02. Did not submit an acute phase specimen, are classified having a recent probable dengue infection. This is due to the fact that $1 \mathrm{gM}$ antibodies for dengue may remain elevated for 2 to 3 months after the illness. The elevated $1 \mathrm{gM}$ observed in a sample could be the result of an infection that occurred 2 to 3 months ago.
Often times both an acute and convalescent phase specimen are needed to make a diagnosis of dengue infection.

While current research and policy interventions often treat dengue expansion as a phenomenon associated with urban human settlement, the incidence of the disease in rural areas is also on the rise.

Beeds et al concluded from their Southeast Australian study that an increased risk of A. aegypti range expansion in Australia was due to the human adaption of installing large domestics water storing containers as a response to persisting regional drying, rather than due to climate change itself Furthermore, dengue and yellow fever caused multiple epidemics in the southern parts of the USA in the 18 th, 19 th, and early 20 th centuries [18].

Taking into account many of the factors described earlier and based on observations made during the 1981 Cuban epidemic of DF/DHF [19].

Kouri and coworkers presented an integral hypothesis in which the association of different factors, such as immunological status, genetic background, host condition, viral strain, and epidemiological and ecological conditions, determines whether or not and to what extent, DHF will be involved in any particular epidemic [20].

\section{Conclusion}

Serological methods such as enzyme linked immune-sorbent assay [ELISA] confirms the presence of a recent or past infection with the detection of IgM and IgG antidengue antibodies.

\section{What this study adds to existing knowledge?}

Since dengue can be mistaken for the diseases yellow fever, measles and influenza. ELISA is best way to confirm diagnosis of dengue by detecting the antibody response and testing for the direct evidence of the virus.

\section{Author's contribution}

Dr. Tamasi Mukherji: Concept, study design

Dr. Mayur Bahan Mukherji: Data analysis, manuscript preparation. 


\section{Reference}

01. WHO. Dengue Guidelines for Diagnosis, Treatment, Prevention and Control. World Health Organization. 2009;(PDF).

Available

at

[Article:https://www.who.int/csr/resources/publicatio ns/dengue_9789241547871/en/][Crossref]

02. Costa RL, Voloch CM, Schrago CG. Comparative evolutionary epidemiology of dengue virus scrotypes. Infect Genet Evol. 2012;12(2)309314.

doi:

[Article:https://doi.org/10.1016/j.meegid.2011.12.01 1][Crossref]

03. University of Sao Paulo's. World's first dengue vaccine now available in Indonesia. The Jakarta Post. 2016 October 25.

Available

[Article:https://www.thejakartapost.com/news/2016/ 10/25/worlds-first-dengue-vaccine-now-available-inindonesia.html][Crossref]

04. Halstead SB. Pathogenesis of denguechallenges to molecular biology. Sci. $1988 ; 239$ (4839)476-481.

doi:

[Article:https://doi.org/10.1126/science.3277268] [Crossref]

05. Rouvinski A, Guardado-Calvo P, Barba-Spaeth G, Duquerroy $S$, Vaney MC, Kikuti CM, et al. Recognition determinants of broadly neutralizing human antibodies against dengue viruses. Nature. 2015;520(7545)109-113.

doi: [Article:https://doi.org/10.1038/nature14130] [Crossref]

06. World Health Organization (WHO). Dengue and severe dengue- Fact sheet No- 117. WHO. 2013. Available

from:

[Article:http://www.who.Int/mediacentre/factsheets/f s117/en][Crossref]

07. Kumar R, Tripathi S, Tambe JJ, Arora V, Srivastava A, Nag VL. Dengue encephalopathy in children in Northern India- clinical features and comparison with non-dengue. J Neurol Sci. 2008;269(1-2)41-48.

doi:

[Article:https://doi.org/10.1016/j.jns.2007.12.018]

[Crossref]
08. East S. World's first dengue fever vaccine launched in the Philippines. CNN. April 6, 2016.

Available

at

[Article:https://edition.cnn.com/2016/04/06/health/d engue-fever-vaccine-philippines/index.html]

[Crossref]

09. Pinheiro FP, Corber SJ. Global situation of dengue and dengue haemorrhagic fever, and its emergence in the Americas. World Health Statistics Quarterly. 1997;50(3-4)1-169.

[Crossref]

10. National Vector Borne Diseases Control Programme (NVBDCP) Government of India. Guidelines for clinical management of dengue fever. NVBDCP. 2014. Available at Guidelines2014.pdf [Article:

http://www.nvbdcp.gov.in/Doc/Dengue-National-] [Crossref]

11. Bhatt S, Gething PW, Brady OJ, Messina JP, Farlow AW, Moyes $\mathrm{CL}$, et al. The global distribution and burden of dengue. Nature. 2013;496(7446)504-507.

doi: [Article:https://doi.org/10.1038/nature12060] [Crossref]

12. National Vector Borne Diseases Control Programme (NVBDCP). Directorate- General of Health Services, Government of India. Dengue cases and deaths in the country since. 2010.

Available at [Article:http://www.nvbdcp.gov.inldencd.html][Crossref]

13. Nationa1 Vector Borne Diseases Control Programme (NVBDCP), Government of India. Manual on integrated vector management. NVBDCP. 2015.

Available at [Article:http://www.nvbdcp.gov.in/Doc/IVM-ManualDrafl-2015.pdf][Crossref]

14. Jain S, Mittal A, Sharma SK, Upadhyay AD, Pandey RM, Sinha $S$, et al. Predictors of denguerelated mortality and disease severity in a tertiary care center in North India. Open Forum Infect Dis. 2017;5(4)ofx056.

doi: [Article:https://doi.org/10.1093/ofid/ofx056] [Crossref]

15. Bhatt S, Gething PW, Brady OJ, Messina JP, Farlow AW, Moyes $\mathrm{CL}$ et al. The global distribution and burden of dengue. Nature. 2013;496(7446)504-507.

doi: [Article:https://doi.org/10.1038/nature12060] [Crossref] 
16. Dengue virus. Pathogen Information (Path Info). Virginia Bioinformatics Institute. Virginia Tech. [Crossref]

17. World Health Organization (WHO). Dengue vaccine- WHO Position Paper. WHO. 2016.

Available at [Article:http://www.who.int/wer/2016/wer9130.pdf? $\mathrm{ua}=1]$ [Crossref]

18. Ahluwalia G, Sharma SK. Dengue- Current trends and challenges - An Indian perspective. J Assoc Physicians India. 2004;52;561-563. [Crossref]
19. Gubler DJ. The global emergence/resurgence of arboviral diseases as public health problems. Arch Med Res. 33(4)330-342.

doi: [Article:https://doi.org/10.1016/s01884409(02)00378-8][Crossref]

20. Gulati S, Maheshwari A. Atypical manifestations of dengue. Trop Med Int Health. 2007;12(9)1087-1095.

doi: [Article:https://doi.org/10.1111/j.13653156.2007.01891.x][] 